\title{
Preparation and characterisation of gels based on sucrose modified with glycidyl methacrylate
}

\author{
L. Ferreira ${ }^{a}$, M.M. Vidal ${ }^{a}$, C.F.G.C. Geraldes ${ }^{b}$, M.H. Gil ${ }^{a, *}$ \\ ${ }^{a}$ Departamento de Engenharia Química, Universidade de Coimbra, Largo Marquês de Pombal, 3000 Coimbra, Portugal \\ ${ }^{\mathrm{b}}$ Departamento de Bioquímica, Universidade de Coimbra, Apartado 3126, 3000 Coimbra, Portugal
}

Received 27 November 1998; received in revised form 8 March 1999; accepted 27 April 1999

\begin{abstract}
Sugar-based hydrogels were prepared by non-selective modification of sucrose with the introduction of vinyl groups. Sucrose was reacted with glycidyl methacrylate (1:1 molar ratio) in DMSO and in the presence of 4-(N,N-dimethylamino)pyridine (4-DMAP) as catalyst. The structure of the product (SucMA) was established using ${ }^{1} \mathrm{H}$ NMR, ${ }^{1} \mathrm{H}$ DQF-COSY NMR and ${ }^{13} \mathrm{C}$ NMR analysis. Gels were prepared by copolymerisation of hydroxyethyl methacrylate (HEMA) and SucMA in a 70:30 ethylene glycol/water mixed solvent using ammonium persulphate/sodium methabisulphite pair as initiating system. The swelling behaviour of these gels was evaluated as a function of crosslinker content, copolymer composition, $\mathrm{pH}$ and ionic strength. In addition, the diffusional behaviour of sodium salycilate (SSA) from these gels and poly(HEMA) gels is also reported. (C) 2000 Elsevier Science Ltd. All rights reserved.
\end{abstract}

Keywords: Sucrose; Glycidyl methacrylate; Gels; Swelling; Drug release

\section{Introduction}

Sucrose is the most abundant of all sugars presenting advantages due to its high world production (more than 110 million tonnes in 1992) and, consequently, low cost (Khan, 1995; Vlitos, 1995). The high hydrophilicity of the sucrose molecule suggests high biocompatibility levels, which confers it a potential as a material for the preparation of gels. These gels are a good approach to develop nontoxic, highly absorbent materials for use in applications such as general water absorbents, water treatment additives and biomedical devices (Chen, Dordick \& Rethwisch, 1995a).

In order to obtain sucrose based gels, the sucrose molecule must be modified through the incorporation of vinyl groups. According to the literature, this has been accomplished mainly in an enzymatic way (Chen, Martin, Neubauer, Dordick \& Rethwisch, 1995; Patil, Dordick \& Rethwisch, 1991a,b). The major advantage of using enzymes is to obtain regio and stereoselective monomers, involving a unique acylation step, although there are

\footnotetext{
* Corresponding author. Tel.: + 351-39-828392; fax: + 351-39841138.

E-mail address: hgil@eq.uc.pt (M.H. Gil)
}

disadvantages concerning the reduced number of enzymes and acylating agents that can be used in this synthesis (Janssen, Lefferts \& Riet, 1990). Furthermore, the stability of the enzyme in organic solvents and the choice of the right acylating agent are also important problems that may limit the utility of this approach. Therefore, the selective chemical modification of sucrose with vinyl groups has also been reported, although, in this case, specific blocking/deblocking reactions are necessary resulting in a complex and expensive methodology (Fanton, Fayet, Gelas, Deffieux, Fontanille \& Jhurry, 1993; Kunz, 1993; Sachinvala, Niemczura \& Litt, 1991). We are particularly interested in the chemical non-selective modification of sucrose with vinyl groups in order to prepare gels. This approach, to sucrose vinyl monomers synthesis, is easy, rapid and non-expensive.

The present paper describes a chemical procedure for the reaction of sucrose with glycidyl methacrylate involving a unique acylation step. The new monomer was characterised by FTIR and NMR analysis and used to prepare sucrose based gels by copolymerisation with the HEMA monomer. The gels thus obtained were chemically and physically characterised. Results on the degree of swelling as a function of $\mathrm{pH}$, ionic strength, crosslinker content and SucMA/HEMA molar ratio are reported. Finally, we present a drug delivery system, on these sucrose based gels, using SSA as a model drug. 


\section{Experimental part}

\subsection{Materials}

Sucrose (analar) and glycidyl methacrylate $(95 \%$ by GC; systematic name, 2,3-epoxypropyl methylpropenoate) were obtained from BDH Chemicals Ltd. (Poole, UK); 4-(N,NDimethylamino) pyridine (4-DMAP), salicylic acid and dimethyl sulfoxide (DMSO, minimum 99.5\%) were purchased from Sigma Chemical Company (England); hydroxyethyl methacrylate (HEMA, 96\% by GC) was purchased from ACROS Organics (New Jersey, USA); ammonium persulphate and sodium methabisulphite were supplied by May \& Baker Ltd (Dagenham, UK); tripropyleneglycol diacrylate (TPGDA) was obtained from UCB Chemicals.

\subsection{Methods}

NMR: All NMR spectra were recorded on a Varian Unity 500 spectrometer. ${ }^{1} \mathrm{H}$ NMR spectra were recorded in $\mathrm{D}_{2} \mathrm{O}$ $(0.015 \mathrm{M})$, at $499.824 \mathrm{MHz}$, using a pulse angle of $90^{\circ}$ (pulse width of $11 \mu \mathrm{s}$ ) and a relaxation delay of $4 \mathrm{~s}$. The water signal, used as internal reference, was set at $\delta$ $4.75 \mathrm{ppm}$ versus tetramethylsilane and was suppressed by a pre-saturation pulse at water resonance frequency. ${ }^{13} \mathrm{C}$ NMR spectra (proton decoupled) were recorded in $\mathrm{D}_{2} \mathrm{O}$, at $125.695 \mathrm{MHz}$, using a pulse angle of $90^{\circ}$ and a relaxation delay of $10 \mathrm{~s}$. The methyl resonance of tert-butanol, used as internal reference, was set at $\delta 31.2 \mathrm{ppm}$ versus tetramethylsilane. The ${ }^{1} \mathrm{H}$ DQF-COSY spectra was recorded in $\mathrm{D}_{2} \mathrm{O}$, at $499.824 \mathrm{MHz}$. For the acquisition 1024 complex points were used, with $256 \times 2$ increments ("States" acquisition mode) (Piantini, Sorensen \& Ernst, 1982; Rance, Sorensen, Bodenhausen, Wagner, Ernst \& Wuthrich, 1983) and solvent suppression with decoupling. The spectrum was processed in two dimensions with 2048 points using apodizations functions. A total acquisition time of $10 \mathrm{~h}$ was used.

FTIR: FTIR spectra were recorded on a Nicolet-750 spectrometer. The dry samples were powdered, mixed with $\mathrm{KBr}$ and pressed into pellets under reduced pressure. The FTIR spectra were obtained by recording 128 scans between 4000 and $450 \mathrm{~cm}^{-1}$ with a resolution of $2 \mathrm{~cm}^{-1}$.

TLC: TLC was carried out on aluminium precoated plates (silica gel $60, \mathrm{~F}_{254}$, Merck) using the butanol/ acetone $/ \mathrm{H}_{2} \mathrm{O}$ 80:10:10 (v:v:v) eluent. The compounds were detected by spraying the TLC plates with ethanol/ anhysaldeyde/ $\mathrm{H}_{2} \mathrm{SO}_{4}$ 18:1:1 (v:v:v) solution and heating at $100^{\circ} \mathrm{C}$. The $R_{\mathrm{f}}$ values were determined on $10 \mathrm{~cm}$ strips of these plates.

Column chromatography: The Column chromatography was performed according to the procedure described by Still, Kahn and Mitra (1978). The column $\left(10 \times 15 \mathrm{~cm}^{2}\right)$ was filled with silica gel $(40-60 \mu \mathrm{m}$, Merck) and eluted with ethyl acetate/methanol/water 70:5:4 (v:v:v).

\subsection{Synthesis of SucMA (standard procedure)}

Sucrose $(20.0 \mathrm{~g})$ was dissolved in DMSO $(60 \mathrm{ml})$ in a stoppered $250 \mathrm{ml}$ round flask. After the dissolution of 4DMAP (3.5 g), the GMA ( $8.9 \mathrm{ml})$ was added under nitrogen atmosphere. The solution was magnetically stirred at $25^{\circ} \mathrm{C}$ for $72 \mathrm{~h}$, after which the reaction was stopped by adding an equimolar amount of concentrated $\mathrm{HCl}$ to neutralise the 4DMAP. The reaction mixture was precipitated in acetone and the precipitate was dried over calcium chloride under vacuum atmosphere during two weeks, yielding $11.9 \mathrm{~g}$ of a yellow product. Part of the crude product $(7.8 \mathrm{~g})$ was purified by silica gel column chromatography. The isolated product (SucMA), yield $1.2 \mathrm{~g}(10 \%)$, was a mixture of two compounds which had a $R_{\mathrm{f}}$ of 0.64 (main component) and 0.56 , respectively.

\subsection{Gel preparation}

The poly(SucMA-co-HEMA) gels were prepared in $10 \mathrm{ml}$ glass beakers (diameter $2-3 \mathrm{~cm}$ ) by polymerizing the desired amounts of SucMA (155-260 mg), HEMA $(166 \mu \mathrm{l})$, the crosslinker TPGDA $(2-10 \mathrm{~mol} \%$ relative to the monomers) and the ammonium persulphate/sodium methabisulphite $(6 \mathrm{mg}, 1: 2(\mathrm{w} / \mathrm{w}))$ mixture as radical initiator, in $2 \mathrm{ml}$ of the ethylene glycol/water 70:30 (v:v) mixture. After homogenisation, the solutions were bubbled with $\mathrm{N}_{2}$, stoppered and the temperature raised to $55^{\circ} \mathrm{C}$. The polymerization reaction proceeded for $4 \mathrm{~h}$. After this time, a gel was formed and the residual ethylene glycol/water 70:30 (v:v) contained no traces of SucMA (as determined by TLC). The resulting gels were kept overnight at room temperature and they were subsequently separated from the glass by adding some distilled water. Then, to wash the unreacted monomers, gel samples were immersed in distilled water for five days, changing the water every day. The poly(SucMA-co-HEMA) gels were denoted by: poly(SucMAco-HEMA)1-3 with a 1:3 (mol/mol) SucMA/HEMA ratio and 2,5 and $10 \mathrm{~mol} \%$ of TPGDA, respectively; poly(SucMA-co-HEMA)4 with a $1: 1.7$ (mol/mol) SucMA/ HEMA ratio and 2 mol\% of TPGDA.

The general method for poly(HEMA) gels synthesis was as follows: $200 \mu \mathrm{l}$ of HEMA and the desired amount of TPGDA (1-10 mol\% relative to the monomer) was degassed in a $10 \mathrm{ml}$ vial for $5 \mathrm{~min}$. To this solution, $6 \mathrm{mg}$ of ammonium persulphate/sodium methabisulphite 1:2(w/w) was added under $\mathrm{N}_{2}$. Further steps were carried out as described for poly(SucMA-co-HEMA) gels. The poly(HEMA) gels were denoted by: poly(HEMA)1, poly(HEMA)2, poly(HEMA)3, poly(HEMA)4 and poly(HEMA)5 with $1,2,3,5,10 \mathrm{~mol} \%$ (relative to HEMA monomer) of TPGDA.

\subsection{Equilibrium water content determinations}

Equilibrium swelling studies were accomplished by immersing the gels in either a $0.9 \% \mathrm{NaCl}$ solution or in 


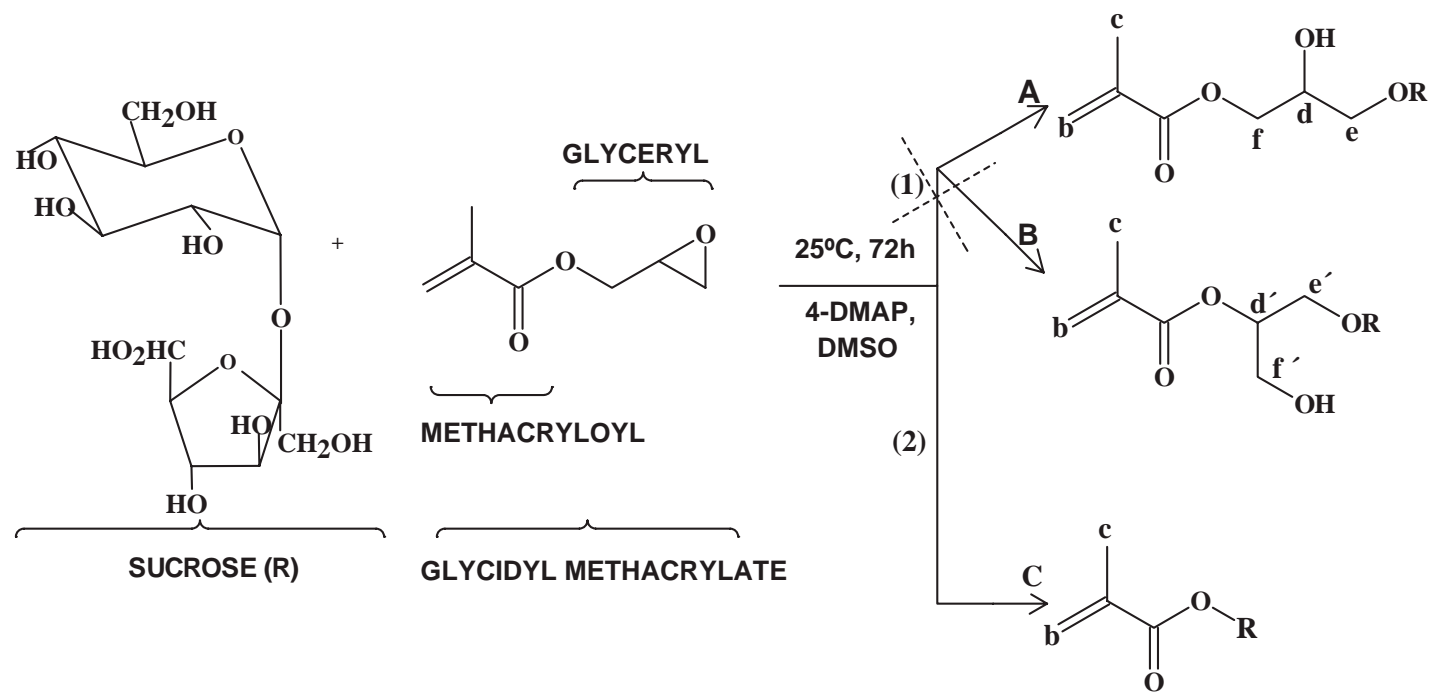

Fig. 1. Schematic representation of the possible mechanisms in sucrose reaction with glycidyl methacrylate: (1) the formation of 1-methacryloyl-1-glyceryl (a) and 2-methacryloyl-1-glyceryl ether of sucrose (b) through the opening of the epoxide ring; (2) the formation of methacrylated sucrose through a transesterification reaction (the protons are assigned in all chemical structures).

solutions of desired $\mathrm{pH}$. The gels were allowed to equilibrate for five days, in sealed containers. After this time, the gels were removed from the solutions, blotted and weighed to determine the equilibrium swelling weight $\left(W_{\mathrm{s}}\right)$. The same gels were dried at room temperature, under vacuum, in the presence of phosphorous pentoxide, until constant weight in order to determine the dried weight, $W_{\mathrm{d}}$. Equilibrium water content (EWC) was determined using Eq. (1):

$\mathrm{EWC}=\frac{W_{\mathrm{s}}-W_{\mathrm{d}}}{W_{\mathrm{s}}} \times 100$

\subsection{SSA release measurements}

After equilibrium in distilled water at $\mathrm{pH} 6.5$, swollen gels were immersed for five days in $10 \mathrm{ml}$ of a salycilic acid aqueous solution $(0.25 \%,(\mathrm{w} / \mathrm{v})), \mathrm{pH} 12.0$ at $25^{\circ} \mathrm{C}$. At this $\mathrm{pH}$, the salycilic acid is converted into sodium salycilate (SSA) (Shane and Routh, 1967). After blotting, the gels were immersed in $50 \mathrm{ml}$ of distilled water at $37^{\circ} \mathrm{C}$ with magnetic stirring $(150 \mathrm{rpm})$. The released SSA was monitored at $300 \mathrm{~nm}$ on an UV-VIS spectrophotometer, until no further changes of absorbance values were observed. These absorbance measurements were converted to SSA concentrations using an SSA calibration curve, and the total amount of SSA released was calculated. To determine the SSA residual concentration, the gels were pulverised, dried at room temperature under vacuum over phosphorous pentoxide and washed with $10 \mathrm{ml}$ of a $\mathrm{NaOH}$ aqueous solution, $\mathrm{pH}$ 12.0. The absorbance of this alkaline solution was determined at $300 \mathrm{~nm}$. Finally, SSA loading $(M \infty)$ was calculated by adding the SSA residual concentration to the concentration of the total amount of SSA released.

\section{Results and discussion}

\subsection{Synthesis of SucMA}

In this work, the reaction conditions of the sucrose derivatisation with the GMA were chosen according to the Hennink work, about a similar reaction involving dextran instead of sucrose (Dijk-Wolthuis, Franssen, Talsma, Steenbergen, Bosch \& Hennink, 1995; Franssen, Vos \& Hennink, 1997; Smedt, Lauwers, Demeester, Steenbergen, Hennink \& Roefs, 1995). Therefore, the reaction reported between sucrose and GMA, occurred in DMSO using 4-DMAP as catalyst. From our FTIR results we observed no incorporation of GMA in the absence of the catalyst. The role of the 4-DMAP has been described in the literature either as a Bronsted base, that polarises the hydroxyl groups (Dijk-Wolthuis et al., 1995; Vervoort, Mooter, Augustijns, Busson, Toppet \& Kinget, 1997), or as a nucleophilic agent promoting the formation of the metacryloyl pyridinium salt (Vervoort et al., 1997). Considering these two mechanisms, Fig. 1 represents the possible products for the reaction of sucrose with GMA. Our NMR results indicate that the reaction occurs by a transesterification mechanism (route 2 in Fig. 1). The yield of the reaction with sucrose $(10 \%)$ is quite low when compared with the yield of the similar reactions involving polysaccharides, 70-90\% for dextran (Dijk-Wolthuis et al., 1995) and $10-50 \%$ for inulin (Vervoort et al., 1997). This can most likely be ascribed either to the lower reactivity of sucrose as a nucleophilic agent, or to the purification methods used acetone precipitation and column chromatography instead of dialysis, which is only applied in the case of polysaccharides. 


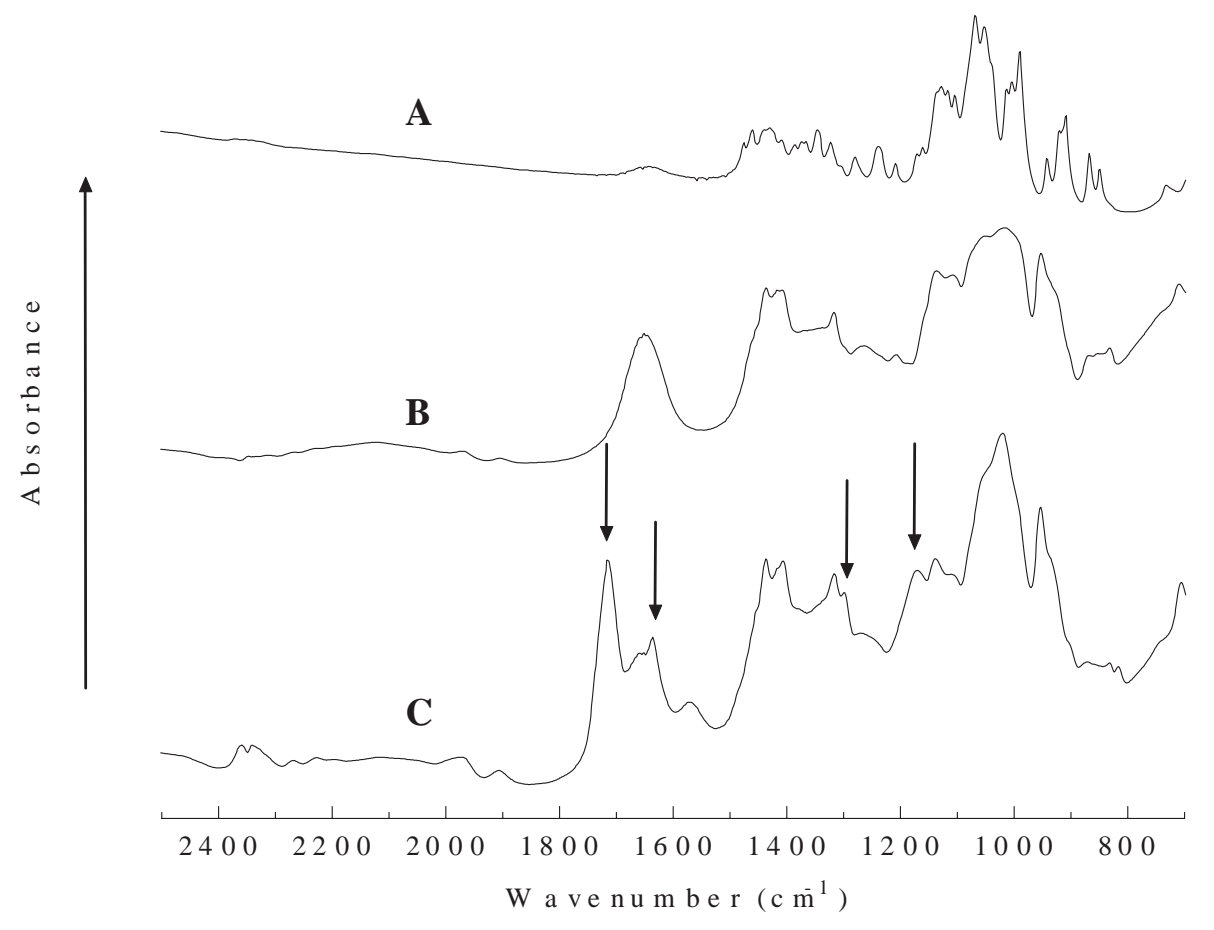

Fig. 2. Absorbance FTIR spectra of sucrose (a), the product obtained in the reaction of sucrose with glycidyl methacrylate without (b) and in the presence (c) of the 4-DMAP (SucMA). The arrows indicate the peaks, appearing at $1179,1295,1636$ and $1716 \mathrm{~cm}^{-1}$, which originate from the methacrylate groups.

\subsection{Characterization of SucMA}

Fig. 2 shows the FTIR spectra of sucrose (A) and of sucrose modified with GMA in the absence (B) and in the presence $(\mathrm{C})$ of the 4-DMAP. In spectrum $\mathrm{C}$ new bands appear at 1716 and $1636 \mathrm{~cm}^{-1}$, which can be assigned, respectively, to the carbonyl group $(\nu \mathrm{C}=\mathrm{O})$ and to the double bond $(\nu \mathrm{C}=\mathrm{C})$ characteristic of the methacrylate group, and at 1295 and $1179 \mathrm{~cm}^{-1}$, which can be assigned to the ester bonds $(\nu \mathrm{C}-\mathrm{O})$ established between the sucrose and the GMA. At the same time, the absence of these bands in spectrum B suggests that the monomer SucMA was synthesised only in the presence of the catalyst.

The product obtained from the reaction between sucrose and GMA, in the presence of 4-DMAP (SucMA), was also characterised by NMR. Fig. 3 shows the ${ }^{1} \mathrm{H}$ NMR spectra of sucrose and the SucMA product (spectra A and B, respectively). The assignments of the ${ }^{1} \mathrm{H}$ signals of sucrose were obtained from the literature (Timmermans, Waard, Tournois \& Leeflang, 1993). In spectrum B the multiplets from the methacryloyl group are observed at $\delta 1.90 \mathrm{ppm}$ (methyl protons, $\mathrm{H}_{\mathrm{c}}$ ) as well as at $\delta 6.14$ and $5.72 \mathrm{ppm}$ (protons at the double bond, $\mathrm{H}_{\mathrm{b}}$ ), having an integral ratio of $3: 2$. The formation of the product SucMA is also confirmed by the respective ${ }^{13} \mathrm{C}$ NMR spectrum, displayed in Fig. 4(b). Here, the signals of methacryloyl group are detected at $\delta 171.0$ $\left(\mathrm{C}_{\mathrm{d}}\right), \delta 137.2\left(\mathrm{C}_{\mathrm{b}}\right), \delta 128.8\left(\mathrm{C}_{\mathrm{a}}\right)$ and $\delta 19.0\left(\mathrm{C}_{\mathrm{c}}\right) \mathrm{ppm}$.

While the presence of the methacryloyl group in SucMA is supported by the ${ }^{1} \mathrm{H},{ }^{13} \mathrm{C}$ and ${ }^{1} \mathrm{H}$ DQF-COSY NMR (see later) data discussed above, the presence of the glyceryl part is not. In fact, our NMR results suggest that the reaction did not take place at the epoxide ring, but rather through a transesterification mechanism (route 2 in Fig. 1). Based on the assignment of ${ }^{1} \mathrm{H}$ NMR glyceryl methacrylate spectrum (Dijk-Wolthuis et al., 1995), the signals at $\delta 5.2 \mathrm{ppm}$ and $\delta$ $4.4 \mathrm{ppm}$ in the ${ }^{1} \mathrm{H}$ spectrum of SucMA (Fig. 3(b)) could be correlated to the proton $\mathrm{H}_{\mathrm{d}^{\prime}}$ of the 2-glyceryl methacrylate, or to the proton $\mathrm{H}_{\mathrm{f}}$ of the 1-glyceryl methacrylate, respectively (route 1 in Fig. 1). However, no signals from the carbons linked to $\mathrm{H}_{\mathrm{d}^{\prime}}$ and $\mathrm{H}_{\mathrm{f}}$ could be detected, in the ${ }^{13} \mathrm{C}$ NMR spectrum (Fig. 4(b)), which according to the literature (Vervoort et al., 1997) should appear at $\delta 76.0 \mathrm{ppm}\left(\mathrm{C}_{\mathrm{d}^{\prime}}\right)$ and $\delta 66.0 \mathrm{ppm}\left(\mathrm{C}_{\mathrm{f}}\right)$. Moreover, it is not possible to see in the ${ }^{13} \mathrm{C}$ NMR of SucMA (Fig.4(b)) the signal that should result from the carbon of the glyceryl part at the ether function, which according to the literature, should appear in the region within $\delta 70.0$ and $\delta 72.0 \mathrm{ppm}$. These results suggests that SucMA is an ester instead of an ether and that the mechanism followed can be similar to the one suggested by Vervoort et al. (1997): a nucleophilic catalysis of 4DMAP with the formation of a methacryloyl pyridinum salt intermediate followed by a general base catalysis. The presence of a transesterification mechanism was also observed for the reaction between glycidyl methacrylate and dextran (Dijk-Wolthuis, Bosch, Hoof \& Hennink, 1997) or inulin (Vervoort et al., 1997), leading to the direct attachment of the methacryloyl group to hydroxyl groups in the polysaccharides.

The ${ }^{13} \mathrm{C}$ NMR spectrum of SucMA, besides the signals of the methacryloyl group and the sucrose carbon atoms, 

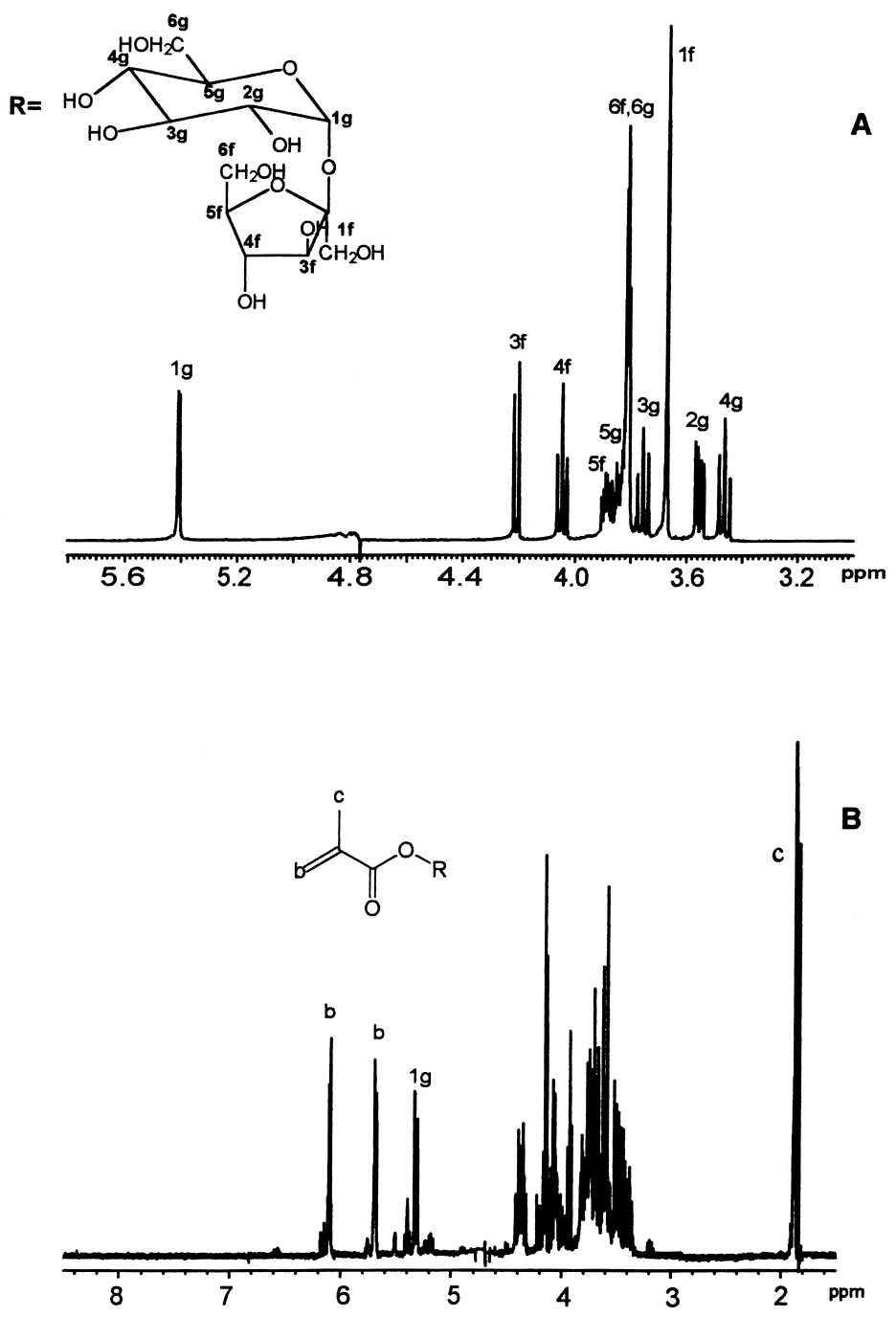

Fig. 3. ${ }^{1} \mathrm{H}$ NMR spectra of sucrose (a) and SucMA (b) obtained in $\mathrm{D}_{2} \mathrm{O}\left(25^{\circ} \mathrm{C}\right)$.

shows several additional peaks. These can be attributed to the shifts of the sucrose ${ }^{13} \mathrm{C}$ resonances induced by the attachment of the methacryloyl group (Yoshimoto, Itatan \& Suda, 1980). Based on the TLC results, that confirm the presence of two compounds, and according to the literature (Khan, 1995), we conclude that the derivatisation of sucrose, probably takes place at the C-6 hydroxyl of the glucose unit or the C-6 $6^{\prime}$ hydroxyl of the fructose unit, due to the higher acidity of a primary hydroxyl and also to the lower steric hindrance of these positions.

In the ${ }^{1} \mathrm{H}$ NMR of sucrose (Fig.3(a)) the signal from the anomeric proton $\left(\mathrm{H}_{1 \mathrm{~g}}\right)$ of the glucopyranosyl ring is observed at $\delta 5.4 \mathrm{ppm}\left(1\right.$ doublet, $\left.\mathrm{J}_{\mathrm{H}, \mathrm{H}}^{1,2}=3.90 \mathrm{~Hz}\right)$, well separated from the other proton signals $(\delta 3.4-4.2 \mathrm{ppm})$. However, in the ${ }^{1} \mathrm{H}$ NMR spectrum of SucMA (Fig.3(b)) this signal is slightly displaced to $\delta 5.36 \mathrm{ppm}$ in the form of two doublets $\left(\mathrm{J}_{\mathrm{H}, \mathrm{H}}^{1,2}=3.90 \mathrm{~Hz}\right)$, probably, due to the existence of 2 different monomers. In the ${ }^{1} \mathrm{H}$ DQF COSY spectrum (Fig. 5) this signal is correlated with another at $\delta$ $3.5 \mathrm{ppm}$, which corresponds to protons $\mathrm{H}_{2 \mathrm{~g}}$ from the glucose residue of the sucrose molecule, as expected. This result confirms the integrity of the sucrose molecule after the reaction. Finally, in order to know the degree of substitution (DS) in SucMA, the ratio between the average integral of the protons at the double bond ( $\delta 5.72$ and $\delta 6.1 \mathrm{ppm})$ and the integral of the anomeric proton $(\delta 5.36 \mathrm{ppm})$ was calculated, having an integral ratio of $1: 1$. This result confirmed the synthesis of a mono-substituted compound.

\subsection{Characterisation of the Poly(SucMA-co-HEMA) gels}

\subsubsection{Equilibrium water content}

According to the literature, gels prepared solely from sugar monomers present a relatively low EWC, which was explained by the strong sugar-sugar interactions (Martin, Ampofo, Linhardt \& Dordick, 1983). In this work, to avoid this tight packing of the sugars moieties, copolymerization of SucMA with HEMA was carried out, by following the Refojo method for the preparation of the Poly(HEMA) gels (Refojo \& Yasuda, 1965). 

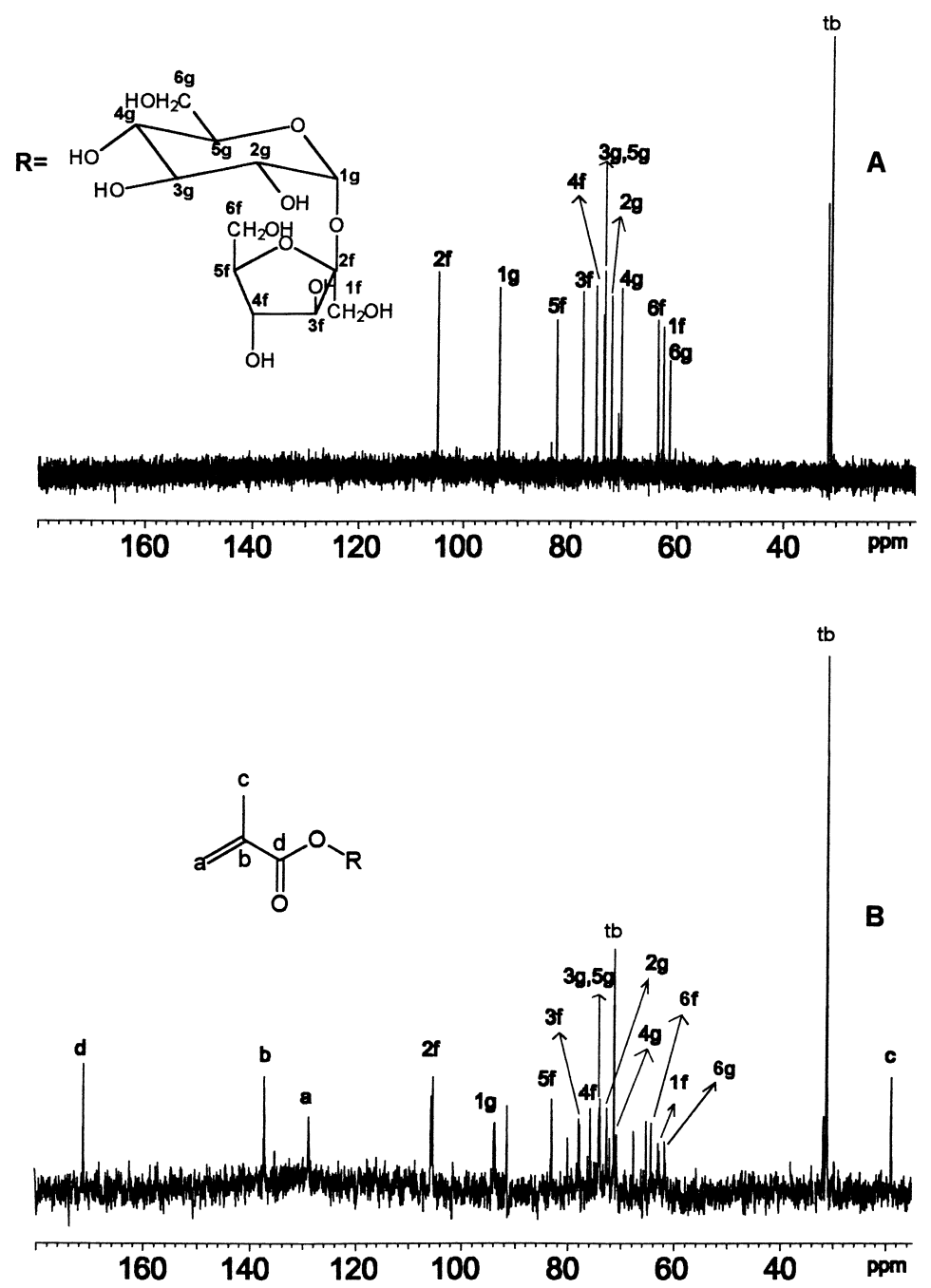

Fig. 4. ${ }^{1} \mathrm{H}$ DQF-COSY spectrum of SucMA obtained in $\mathrm{D}_{2} \mathrm{O}\left(25^{\circ} \mathrm{C}\right)$. The dashed lines represent some protons correlations (see text).

Figs. 6 and 7 show the EWC of poly(SucMA-co-HEMA) gels as a function of the crosslinker content ( $\mathrm{mol} \%)$ and the SucMA/HEMA molar ratio, respectively. As it can be seen by comparing curve $1 \mathrm{~A}$ and curve $2 \mathrm{~A}$ in Fig. 6, poly(SucMA-co-HEMA) gels show higher EWC than the corresponding poly(HEMA) gels. In Fig. 7, we observe that the EWC of the gels increases by $87.5 \%$ when SucMA/HEMA molar ratio increases up to 0.6. Furthermore, curve $2 \mathrm{~A}$ in Fig. 6 shows the typical poly(HEMA) gels behaviour as a function of the crosslinker density. For the highest concentrations of the crosslinker, the polymeric chains get closer to each other, which favours the hydrophobic interactions and leads to lower EWC values (Refojo \& Yasuda, 1965). Comparing curves $1 \mathrm{~A}$ and $2 \mathrm{~A}$, we observe that this effect is less pronounced for the poly(SucMA-co-HEMA) gels, for which the increase of the crosslinker agent could contribute to the reduction of the EWC, in the same way as described for poly(HEMA) gels. However the sucrose molecules work as a restriction to that interactions. The balance of these opposite effects could explain the slight reduction of the EWC observed in poly(SucMA-co-HEMA) gels.
Figs. 6 and 7 also display the EWC results obtained for the poly(SucMA-co-HEMA) and poly(HEMA) gels in an aqueous solution of $\mathrm{NaCl} 0.9 \%$. As it can be seen, poly(HEMA) gels show a lower EWC in the presence of the salt than in distilled water (curves $2 \mathrm{~B}$ and $2 \mathrm{~A}$, respectively). This can be explained by the reduction of the solvent power of water in the presence of certain ions, specially the chloride ion. The presence of this ion makes the solvent/polymer interactions weaker and favours hydrophobic interactions between polymeric chains (Refojo, 1967). This effect is less pronounced for the poly(SucMA-co-HEMA) gels (see curves 1A and 1B in Fig. 6), specially for small crosslinker content values. This might also be explained by the volume of sucrose molecule which could prevent the reorganisation of the polymeric chains in the presence of the salt.

\subsection{Release of SSA from poly(SucMA-co-HEMA) gels: preliminary results}

For the release studies from poly(SucMA-co-HEMA) and poly(HEMA) gels SSA was used as a model drug because: 


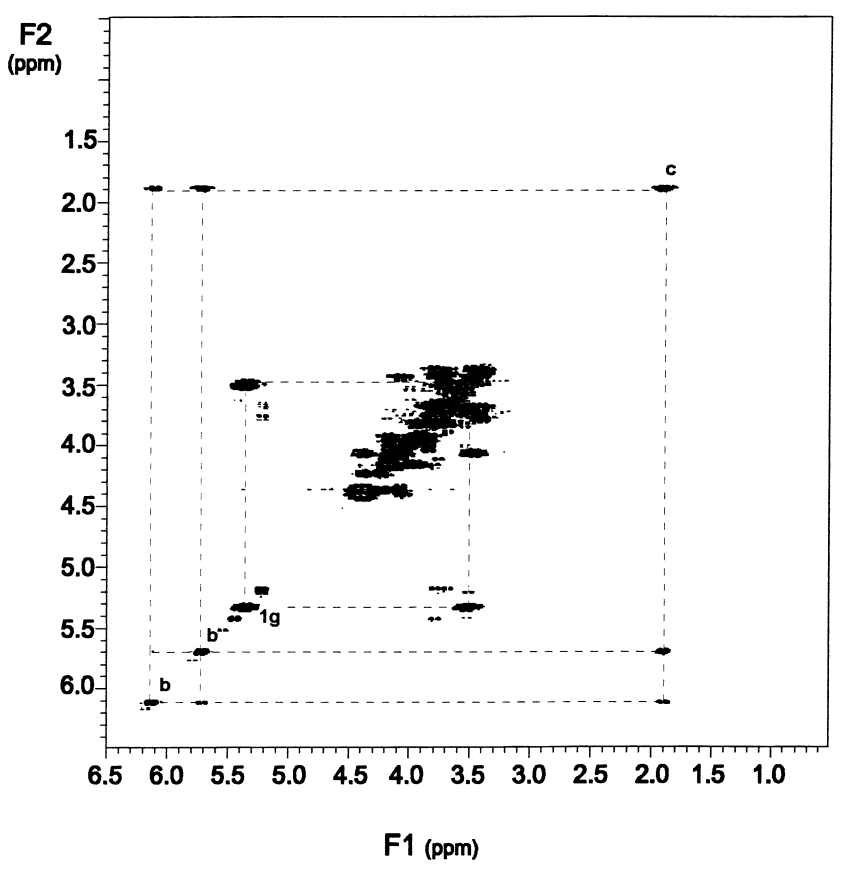

Fig. 5. ${ }^{13} \mathrm{C}$ NMR spectra of sucrose (a) and SucMA (b) obtained in $\mathrm{D}_{2} \mathrm{O}$ $\left(25^{\circ} \mathrm{C}\right)$ (tert-butanol, tb, was used as reference line).

(i) its solubility in water allows high loading of the drug into the polymer matrix from concentrated solutions and (ii) its release into water can be sensitively followed by spectrophotometric measurements at $300 \mathrm{~nm}$. The diffusion coefficients were obtained from Eq. (2) (Peppas \& Klier, 1991):

$\frac{M_{\mathrm{t}}}{M_{\infty}}=\frac{4}{\pi^{1 / 2}}\left(\frac{D t}{l_{o}^{2}}\right)^{1 / 2}$

Here, $l_{\mathrm{o}}$ is the thickness of the gel, $D$ is the diffusion coefficient of the solute in the swollen gel, $M_{\mathrm{t}}$ is the amount of solute released at time $t$, and $M_{\infty}$ is the total amount of solute

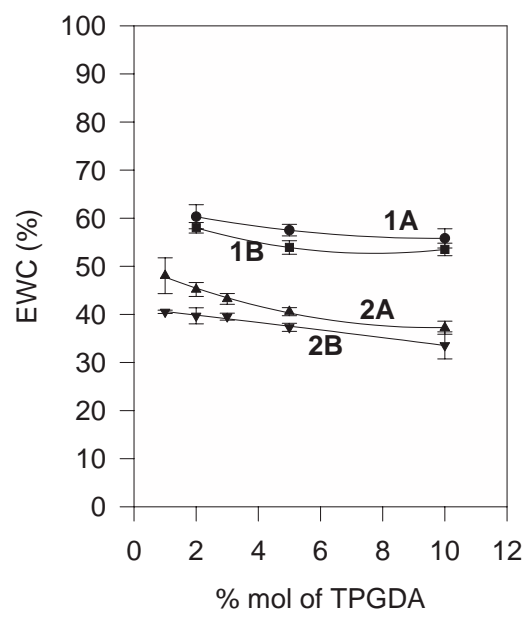

Fig. 6. Variation of the EWC for poly(HEMA) (2) and poly(SucMA-coHEMA) gels (1:3, SucMA/HEMA molar ratio) (1) with different crosslinking densities in distilled water (a) and $0.9 \%$ of $\mathrm{NaCl}$ solution (b), at $\mathrm{pH} 6.5$ (Values of EWC are given as average and standard deviation over three experiments). in the gel. The use of this equation is possible because the thickness of the gels is small $(4.0-6.0 \mathrm{~mm})$ and the diffusion from the gel can be considered as one-dimensional (Blanco, Rego \& Huglin, 1994).

Fig. 8 shows the relative and absolute concentration values of SSA in distilled water, at $37^{\circ} \mathrm{C}$, released from three different poly(SucMA-co-HEMA) gels: one with a 1:1.7 SucMA/HEMA molar ratio and $2 \mathrm{~mol} \%$ of TPGDA, the other two with a 1:3 SucMA/ HEMA molar ratio and a TPGDA content of 2 and $10 \mathrm{~mol} \%$, respectively (see Table 1). Also, Fig. 9 shows the SSA release from poly(HEMA) gels with different crosslinker contents, in the same conditions. As it is shown, the fractional release of SSA, $M_{\mathrm{t}} / M_{\infty}$, is linear with the square root of time, $t^{1 / 2}$, for values of $M_{t} / M_{\infty}$ less than 0.5, for all studied gels. Thus, the release curve profiles match Fick's law (Trigo, Blanco, Teijon \& Sastre, 1994), allowing diffusion coefficient determination from the respective slope.

Table 1 summarises the calculated values for the diffusion coefficients, $t_{50}$ values (time required for the release of $50 \%$ of the total amount of the SSA released) and the total amount of the SSA released from poly(SucMA-coHEMA) and poly(HEMA) gels. As it can be seen, the diffusion coefficient for poly(HEMA) gels does not change, increasing the crosslinker content. However, in poly(SucMA-co-HEMA) gels with 1:3 SucMA/HEMA molar ratio, the increase of crosslinker content leads to a significant increase of the SSA release. Additionally, the poly(SucMA-co-HEMA) gels with small crosslinker content ( $2 \mathrm{~mol} \%$ ) gives a similar diffusion coefficient to that observed for poly(HEMA) gels, even after increasing the SucMA/HEMA molar ratio to 1:1.7 (poly(SucMA-coHEMA)4).

Another interesting remark for poly(SucMA-co-HEMA) gels is related to the SSA loading. Although the poly(SucMA-co-HEMA) gels 1 and 4 (see Table 1) present the same diffusion behaviour as the poly(HEMA) gels, they show a larger loading capacity.

The diffusion of SSA from poly(HEMA) gels and poly(SucMA-co-HEMA) gels is very rapid. As it can be seen from Figs. 8 and 9, 80\% of the SSA release occurs within the range of 35-50 min (depending on the gel composition). The results in Table 2 show that by changing the $\mathrm{pH}$ from neutral $(\mathrm{pH}$ 6.5) to basic conditions $(\mathrm{pH} 12.0)$ there is an increase in gel swelling and physical parameters such as diameter and thickness. The ionisation of the hydroxyl groups of sucrose and HEMA at $\mathrm{pH} 12.0$ could be the reason for this behaviour. The literature $\mathrm{p} K_{\mathrm{a}}$ values for these hydroxyl groups are described between 11 and 12 (Morrison \& Boyd, 1983). The creation of negative charges able to establish ionic bonds with counterions as $\mathrm{Na}^{+}$, could contribute for the increase of ionic strength within the gel. Thus, either the repulsion between the individual chains or the Donnan potential increase could explain the EWC increase, displayed by poly(SucMA-co-HEMA) and poly(HEMA) gels at $\mathrm{pH}$ 12.0. This mechanism could explain the higher 


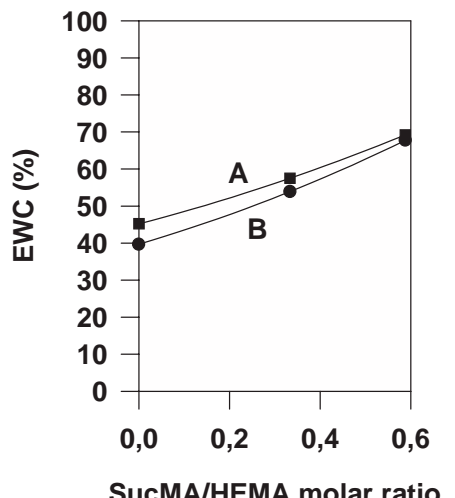

Fig. 7. Variation of the EWC for poly(SucMA-co-HEMA) gels prepared with different SucMA/HEMA molar ratios and the same crosslinking density ( $5 \mathrm{~mol} \%$ of TPGDA) in distilled water (a) and $0.9 \%$ of $\mathrm{NaCl}$ solution (b), at $\mathrm{pH} 6.5$.

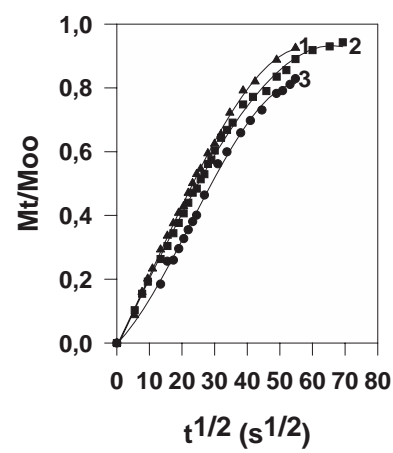

(a)

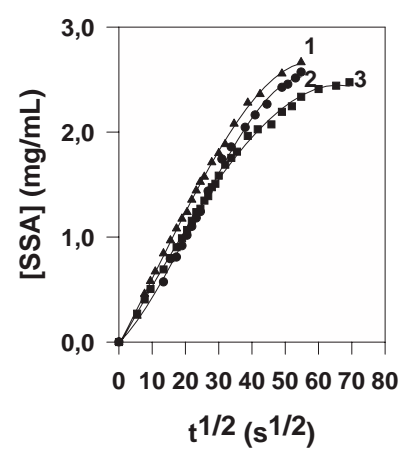

(b)
Fig. 8. Representation of the fractional release (a) and absolute concentration release $(\mathrm{mg} / \mathrm{ml})$ of SSA (b), for three poly(SucMA-co-HEMA) gels (in water, pH 6.5, 37 ${ }^{\circ}$ ): (1) poly(SucMA-co-HEMA)3, (2) poly(SucMA-coHEMA)1 and (3) poly(SucMA-co-HEMA)4.

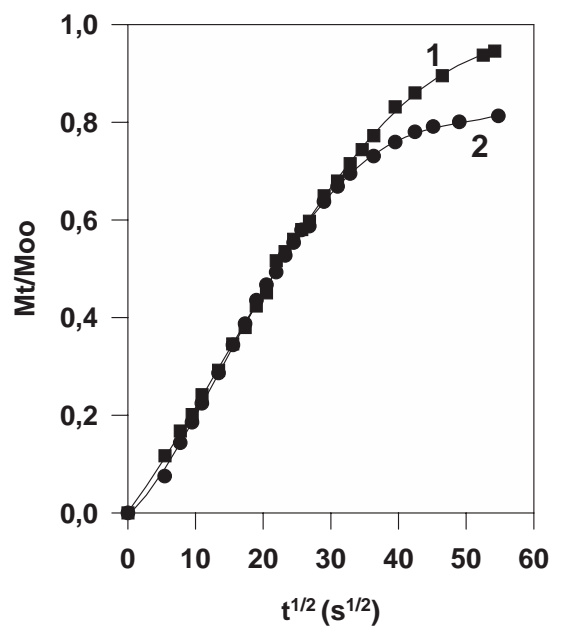

(a) loading contents displayed by poly(SucMA-co-HEMA) relative to poly(HEMA) gels. The increase of SucMA/ HEMA molar ratio leads to a higher content of hydroxyl groups which can justify, according to the above mechanism, the larger load capacity observed. Further, the EWC increase for $\mathrm{pH} 12.0$ might explain the high diffusion coefficients for poly(HEMA) and poly(SucMA-co-HEMA) gels. Probably the increase of EWC corresponds to an increase of free or bulk water which is not attached to the polymer chains (Khare \& Peppas, 1993). This water can increase solute diffusity and permeability, explaining the high values for diffusion coefficients obtained.

\section{Conclusions}

Incorporation of vinyl groups in sucrose was accomplished through its reaction with GMA in DMSO and in the presence of 4-DMAP as catalyst. ${ }^{1} \mathrm{H},{ }^{13} \mathrm{C}$ and ${ }^{1} \mathrm{H}-\mathrm{DQF}$ COSY NMR spectroscopic data also revealed that the methacryloyl group was attached directly to sucrose molecule and, as a consequence, the product obtained was identified as an ester rather than an ether. The TLC results showed that the product was a mixture of two mono-substituted compounds (one of them in a larger amount). Upon copolymerization of SucMA with HEMA in an ethylene glycol/water mixture, using the pair ammonium persulphate/sodium methabisulphite as initiator, it is feasible to obtain gels. These gels had remarkable EWC values compared with those of poly(HEMA) gels. The EWC of poly(SucMA-co-HEMA) gels is less dependent upon crosslinker content and on the presence of the salt $(0.9 \% \mathrm{NaCl})$, as shown by poly(HEMA) gels. The results obtained from the SSA release studies ( $\mathrm{pH}$ 12.0) showed that the values of the diffusion coefficients from poly(SucMA-co-HEMA), with small crosslinker contents, were similar to those of

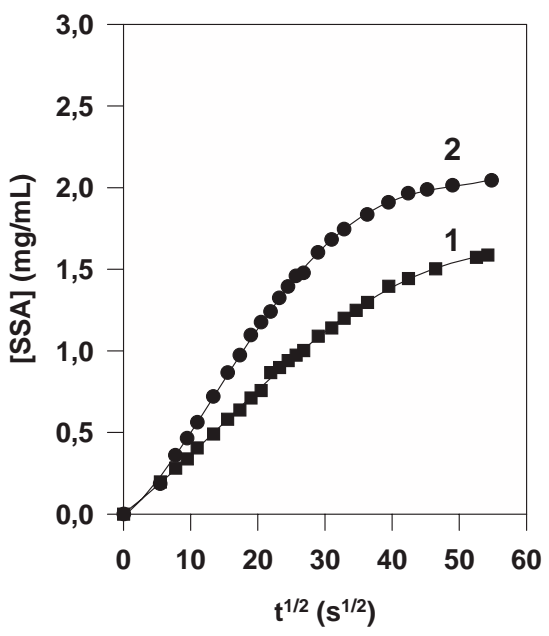

(b)

Fig. 9. Representation of the fractional release (a) and absolute concentration release (mg/ml) of SSA (b), for two poly(HEMA) gels (in water, $\mathrm{pH} 6.5,37^{\circ} \mathrm{C}$ ): poly(HEMA)1 (1) and poly(HEMA)5 (2). 
Table 1

Diffusion coefficients, $t_{50}$ and loading capacity displayed by poly(SucMA-co-HEMA) gels in release studies

\begin{tabular}{|c|c|c|c|c|c|}
\hline Gel & SucMA/HEMA molar ratio & TPGDA (mol\%) & $t_{50}(\min )$. & $D\left(\mathrm{~m}^{2} \mathrm{~s}^{-1}\right)$ & $(\mathrm{SSA})_{\mathrm{total}}=M_{\infty}(\mathrm{mg} / \mathrm{ml})$ \\
\hline Poly(HEMA)1 & - & 1 & 8 & $5.2 \times 10^{-10}$ & 1.68 \\
\hline Poly(HEMA)2 & - & 10 & 8 & $5.2 \times 10^{-10}$ & 2.52 \\
\hline Poly(SucMA-co-HEMA)1 & $1: 3$ & 2 & 10 & $5.0 \times 10^{-10}$ & 2.62 \\
\hline Poly(SucMA-co-HEMA)3 & $1: 3$ & 10 & 9 & $1.1 \times 10^{-9}$ & 2.88 \\
\hline Poly(SucMA-co-HEMA)4 & $1: 1.7$ & 2 & 13 & $5.1 \times 10^{-10}$ & 3.10 \\
\hline
\end{tabular}

Table 2

EWC and physical properties displayed by poly(HEMA) and poly(SucMA-co-HEMA) gels in contact with aqueous solution at pH 6.5 and pH 12.0

\begin{tabular}{|c|c|c|c|c|c|c|}
\hline \multirow[b]{2}{*}{ Gel } & \multicolumn{3}{|c|}{ Distilled water ( $\mathrm{pH} 6.5)$} & \multicolumn{3}{|c|}{$\mathrm{NaOH}$ aqueous solution (pH 12.0) } \\
\hline & Diameter $(\mathrm{cm})$ & Thickness (mm) & EWC $(\%)$ & Diameter $(\mathrm{cm})$ & Thickness (mm) & $\mathrm{EWC}(\%)$ \\
\hline Poly(HEMA)1 & 1.6 & 1.4 & 48.0 & 2.7 & 3.5 & 54.5 \\
\hline Poly(HEMA)5 & 1.6 & 1.5 & 37.2 & 3.1 & 3.5 & 80.0 \\
\hline Poly(SucMA-co-HEMA)1 & 1.7 & 2.0 & 60.1 & 2.7 & 4.0 & $\mathrm{ND}^{\mathrm{a}}$ \\
\hline Poly(SucMA-co-HEMA)3 & 1.6 & 2.7 & 55.8 & 2.4 & 6.0 & 86.0 \\
\hline Poly(SucMA-co-HEMA)4 & 2.0 & 2.4 & 69.2 & 3.1 & 4.5 & 88.9 \\
\hline
\end{tabular}

${ }^{\mathrm{a}} \mathrm{ND}=$ Not determined.

poly(HEMA) gels with a different crosslinker content. However, the poly(SucMA-co-HEMA) gels have a larger SSA loading capacity. A mechanism which involves the ionisation of the sucrose hydroxyl was described to explain the rapid diffusion of SSA (pH 12.0) from poly(SucMA-coHEMA) and poly(HEMA) gels.

\section{Acknowledgements}

We wish to thank Rui Rodrigues for assistance in the acquisition of NMR spectra and Prof. Margarida C.A. Castro for helping in NMR assignments. The authors wish to thank FCT, Portugal, for the grant (FMRH//4413) to Lino Ferreira and financial support from PRAXIS project 2/ 2.2/ SAU/ 1194/95 and the BIOMED II ("MACE" project).

\section{References}

Blanco, M. D., Rego, J. M., \& Huglin, M. B. (1994). Drug release with simultaneous dimensional changes from a new copolymeric hydrogel. Polymer, 35 (16), 3487-3491.

Chen, X., Dordick, J. S., \& Rethwisch, D. G. (1995). Chemoenzymatic synthesis and characterization of poly $(\alpha$-methyl galactoside 6-acrylate) hydrogels. Macromolecules, 28, 6014-6019.

Chen, X., Martin, B. D., Neubauer, T. K., Linhardt, R. J., Dordick, J. S., \& Rethwisch, D. G. (1995). Enzymatic and chemoenzymatic approaches to synthesis of sugar-based polymers and hydrogels. Carbohydrate Polymers, 28, 15-21.

Dijk-Wolthuis, W. N. E., Bosch, J. J. K., Hoof, A. K., \& Hennink, W. E. (1997). Reaction of dextran with glycidyl methacrylate: an unexpected transesterification. Macromolecules, 30, 3411-3413.

Dijk-Wolthuis, W. N. E., Franssen, O., Talsma, H., Steenbergen, M. J., Bosch, J. J. K., \& Hennink, W. E. (1995). Synthesis, characterization and polymerization of glycidyl methacrylate derivatized dextran. Macromolecules, 28, 6317-6322.

Fanton, E., Fayet, C., Gelas, J., Deffieux, A., Fontanille, M., \& Jhurry, D. (1993). Synthesis of 4-O- and 6-O-monoacryloyl derivatives of sucrose by selective hydrolysis of 4,6-O-(1-ethoxy-2-propenylidene)sucrose. Polymerization and copolymerization with styrene. Carbohydrate Research, 240, 143-152.

Franssen, O., Vos, O. P., \& Hennink, W. E. (1997). Delayed release of a model protein from enzymatically-degrading dextran hydrogels. Journal of Controlled Release, 44, 237-245.

Janssen, A. E. M., Lefferts, A. G., \& Riet, K. (1990). Enzymatic synthesis of carbohydrate esters in aqueous media. Biotechnology Letters, 12, $711-716$

Khan, R. (1995). Sucrose: its potential as a raw material for food ingredients and for chemicals. In M. Mathlouth \& P. Reiser (Eds.), Sucrose: properties and applications, Glasgow: Blackie.

Khare, A. R., \& Peppas, N. A. (1993). Investigation of hydrogel water in polyelectrolyte gels using differential scanning calorimetry. Polymer, 34 (22), 4736-4739.

Kunz, M. (1993). From sucrose to semisynthetical polymers. In G. Descostes (Ed.), Carbohydrates as organic raw materials, (pp. 135). VCH.

Martin, B. D., Ampofo, S. A., Linhardt, R. J., \& Dordick, J. S. (1992). Biocatalytic synthesis of sugar-containing poly(acrylate) based hydrogels. Macromolecules, 25, 7081-7085.

Morrison, R., Boyd, R. (1983). Organic chemistry (9th ed.). (Ed.) FundaÇão Calouste Gulbenkian. Lisboa.

Patil, D. R., Dordick, J. S., \& Rethwisch, D. G. (1991). Chemoenzymatic synthesis of a sucrose-containing polymers. Macromolecules, 24, 3462-3463.

Patil, D. R., Rethwisch, D. G., \& Dordick, J. S. (1991). Enzymatic synthesis of a sucrose-containing linear polyester in nearly anhydrous organic media. Biotechnology and Bioengineering, 37, 639-646.

Peppas, N. A., \& Klier, J. (1991). Controlled release by using poly(methacrylate acid-g-ethylene glycol)hydrogels. Journal of Controlled Release, 16, 203-214.

Piantini, U., Sorensen, O. W., \& Ernst, R. R. (1982). Multiple quantum filters for elucidating NMR coupling networks. Journal of American Chemical Society, 104, 6800-6801. 
Rance, M., Sorensen, O. W., Bodenhausen, G., Wagner, G., Ernst, R. R., \& Wuthrich, K. (1983). Improved spectral resolution in COSY ${ }^{1} \mathrm{H}$ NMR Spectra of proteins via double quantum filtering. Biochemical and Biophysical Research Communications, 117, 479-485.

Refojo, M. F. (1967). Hydrophobic interaction in poly(2-hydroxyethyl methacrylate)homogeneous hydrogel. Journal of Polymer Science, 5, 3103-3113.

Refojo, M. F., \& Yasuda, H. (1965). Hydrogels from 2-hydroxyethyl methacrylate and propylene glycol monoacrylate. Journal of Applied Polymer Science, 9, 2425-2435.

Sachinvala, N. D., Niemczura, W. P., \& Litt, M. H. (1991). Monomers from sucrose. Carbohydrate Research, 21, 144-147.

Shane, N. A., \& Routh, J. I. (1967). Use of isosbestic point as a base line in differential spectrophotometry. Analytical Chemistry, 39, 414.

Smedt, S. C., Lauwers, A., Demeester, J., Steenbergen, M. J., Hennink, W. E., \& Roefs, S. P. F. M. (1995). Characterization of the network structure of dextran glycidyl methacrylate hydrogels by studying the rheologica and swelling behaviour. Macromolecules, 28, 5082-5088.
Still, W. C., Kahn, M., \& Mitra, A. (1978). Rapid chromatography technique for preparative separation with moderate resolution. Journal of Organic Chemistry, 43, 2923-2925.

Timmermans, J. W., Waard, P., Tournois, H., \& Leeflang, B. R. (1993). NMR spectroscopy of nystose. Carbohydrate Research, 43, 379-384.

Trigo, R. M., Blanco, M. D., Teijon, J. M., \& Sastre, R. (1994). Anticancer drug, ara-C, release from pHEMA hydrogels. Biomaterials, 15 (14), 1181-1186.

Vervoort, L., Mooter, G. V., Augustijns, P., Busson, R., Toppet, S., \& Kinget, R. (1997). Inulin hydrogels as carriers for colonic drug targeting: I. Synthesis and characterization of methacrylated inulin and hydrogel formation. Pharmaceutical Research, 14 (12), 1730-1737.

Vlitos, A. J. (1995). Economical aspects of sugar. In M. Mathlouth \& P. Reiser (Eds.), Sucrose: properties and applications, Glasgow: Blackie.

Yoshimoto, K., Itatan, Y., \& Suda, Y. (1980). ${ }^{13}$ C-Nuclear Magnetic Resonance (NMR) spectra of $O$-acylglucoses. Additivity of shift parameters and is application to structure elucidations. Chemistry of Pharmaceuetical Bulletin, 28 (7), 2065-2076. 